\title{
Cat Stretch Exercise sebagai Salah Satu Solusi Mengatasi Dismenore pada Remaja Putri
}

\author{
Yunita Wulandari ${ }^{1 *}$, Ika Subekti Wulandari ${ }^{2,}$ Atiek Murharyati ${ }^{3}$ \\ ${ }^{1,2,3}$ Universitas Kusuma Husada Surakarta \\ *Email: yunita.wulandari@ukh.ac.id
}

\begin{abstract}
Background: Dysmenorrhea is a result of menstruation. Dysmenorrhea can cause a variety of complaints in young women such as irregular pain, severe pain and cramps in the lower abdomen that will spread to the back of the back, legs, groin. Cat Stretch Exercise is one of the interventions that is considered to reduce dysmenorrhea pain. The purpose of this study was to determine changes in pain levels in Pondok Imam Bukhari students who were given Cat Stretch Exercise. Methods: The study design used a quasitwo-group pre-test and post-test without control method. Pain measurement with a Numerical Rating Scale (NRS) to assess the level of pain before and after the Cat Stretch Exercise exercise. Respondents in the community service were 31 students who experienced dismenore. Results: Obtained decreased respondents' pain scale from moderate to mild pain. Conclusion: CSE interventions are recommended as one of the non-pharmacological steps to deal with the pain of dysmenorrhea.
\end{abstract}

Keywords: CSE (Cat Stretch Exercise), dismenore, skala nyeri

\section{PENDAHULUAN}

Remaja adalah bagian dari kelompok reproduksi sehat, karena remaja merupakan aset penting untuk terciptanya generasi yang lebih baik. Perubahan pada masa remaja meliputi perubahan secara fisik atau biologis, salah satunya adalah remaja putri mulai mengalami menstruasi atau haid. Masalah ginekologis yang paling sering dialami wanita usia remaja yaitu dismenore (Wong, 2018). Dismenore yang dialami remaja biasa disebut dengan dismenore primer berkaitan dengan sekresi prostaglandin yang ditemukan meingkat pada pasien yang dismenore (Iacovides et al., 2015). Wanita merasakan nyeri atau kram perut bisa 2-3 hari menjelang haid. Nyeri haid yang dirasakan bervariasi, ada yang ringan ada yang berat sehingga tidak bisa menjalankan aktivitas sehari-hari dan membutuhkan banyak istirahat (Chiu et al., 2017; Iacovides et al., 2015; Wong, 2018).

Berbagai intervensi baik farmakologi maupun non farmakologi untuk mengatasi masalah dismenore telah banyak diteliti dan menunjukkan hasil yang efektif, salah satunya adalah cat stretch exercise. Exercise sebagai salah satu manajemen nyeri non farmakologi (Fauziah, 2015). Cat Stretch Exercise merupakan bagian dari Abdominal Stretch Exercise, tujuan dari latihan ini adalah menambah kekuatan otot, daya tahan dan fleksibiltas otot, kebugaran tubuh, optimalisasi daya tangkap, mengurangi ketegangan otot (kram), mengurangi nyeri otot, mengurangi rasa sakit disaat menstruasi, memperbaiki peredaran darah, mengurangi kecemasan, perasaan tertekan, kelelahan, serta membuat perasaan lebih baik (Puspita \& Anjarwati, 2019; Utami, 2014; Vispute et al., 2011).

Berdasarkan wawancara awal dengan kader maupun pengelola pondok pesantren pernah diberikan pendidikan kesehatan atau materi tentang menstruasi tetapi belum pernah diajarkan tentang Cat Stretch Exercise. Dari beberapa siswa yang ditemui 
rata-rata $70 \%$ pernah mengalami nyeri haid dan terbiasa membiarkannya atau mengalihkan dengan aktiviats yang lain. Oleh karena itu kami tertarik untuk memberikan kegiatan penyuluhan tentang menstruasi dan Cat Stretch Exercise pada remaja putri di Pondok Pesantran Imam Bukhori Desa Selokaton Kecamatan Gondangrejo Kabupaten Karanganyar.

\section{TINJAUAN PUSTAKA}

\subsection{Dismenore}

Dismenore merupakan gangguan pada saat menstruasi yang dialami wanita yang dikarakteristikkan dengan adanya nyeri serta kram pada bagian perut bawah yang memungkinkan wanita mengalami penurunan kinerja dan kurang aktifitas sehari-hari. Dismenore adalah nyeri yang terjadi selama atau sesaat sebelum menstruasi, hal inimasalah kandungan yang paling sering pada wanita remaja (Lowdermilk et al., 2015). Berdasarkan jenisnya, dismenore terdiri dari dismenore primer yang artinya nyeri menstruasi, terjadi pada atau sehari sebelum timbulnya menstruasi dan menghilang pada akhir menstruasi. Dismenore diklasifikasikan sebagai primer atau sekunder. Dismenore primer didefinisikan sebagai kram tanpa penyakit yang mendasari. Prostaglandin F2 dan F2 $\alpha$, yang diproduksi oleh rahim dalam konsentrasi yang lebih tinggi selama menstruasi, adalah penyebab utama. Mereka meningkatkan kontraktilitas uterus dan menurunkan aliran darah arteri uterin, menyebabkan iskemia. Hasil akhirnya adalah sensasi kram yang menyakitkan.

Dismenore biasanya menghilang setelah kehamilan pertama dan mungkin tidak terjadi jika siklus anovulasi (Davidson et al., 2012). Pengobatan dismenore primer meliputi kontrasepsi oral (yang menghambat ovulasi); obat antiinflamasi nonsteroid (NSAID) (seperti ibuprofen, aspirin, dan naproxen), yang bertindak sebagai inhibitor prostaglandin; dan tindakan perawatan diri seperti olahraga teratur, istirahat, aplikasi panas, dan nutrisi yang baik (Davidson et al., 2012). Dismenore sekunder berhubungan dengan patologi saluran reproduksi dan biasanya muncul setelah menstruasi. Kondisi yang paling sering menyebabkan dismenore sekunder termasuk endometriosis, penyakit radang panggul residual (PID), stenosis serviks, fibroid rahim, kista ovarium, tumor jinak atau ganas pada panggul atau perut, atau adanya alat kontrasepsi (IUD). Karena dismenore primer dan sekunder dapat hidup berdampingan, diagnosis banding yang akurat sangat penting untuk pengobatan yang tepat (Davidson et al., 2012).

Nyeri pada dismenore sekunder bersifat tumpul, menjalar dari perut bagian bawah ke arah pinggang atau paha, wanita sering kali mengalami perasaan membengkak atau rasa penuh dalam panggul (Lowdermilk et al., 2015). Dismenore kadang-kadang terjadi pada wanita yang juga mengalami menometrorrhagia. Dalam kasus seperti itu, pemeriksaan yang teliti diperlukan untuk menentukan apa yang menyebabkan kedua gejala tersebut. Pengujian dapat meliputi ultrasonografi transvaginal, histerosalpingrografi, dan histeroskopi. Jika pemeriksaan menunjukkan polip endometrium, pengobatan adalah pengangkatan polip dengan pelebaran dan kuretase $(\mathrm{D} \& \mathrm{C})$ rahim. Untuk wanita dengan dismenore berat, 
penggunaan terapi kontrasepsi oral terus menerus, yang tidak memungkinkan terjadinya ovulasi atau menstruasi, mungkin bermanfaat. Histerektomi dapat menjadi pengobatan pilihan jika ada kelainan anatomi. Neurektomi presakral dapat mengendalikan dismenore berat yang disebabkan oleh endometriosis (Davidson et al., 2012).

Kontraksi otot-otot rahim menyebabkan aliran darah menjadi berkurang sehingga meningkatkan aktivitas rahim untuk memenuhi kebutuhan aliran darah (Iacovides et al., 2015). Peningkatan dan pelepasan prostaglandin (terutama $\mathrm{PGF}_{2 \alpha}$ ) dari endometrium saat menstruasi menimbulkan kontraksi uterus yang tidak terkoordinasi dan tidak teratur sehingga menyebabkan nyeri. Wanita dengan riwayat dismenore mempunyai tekanan intra uteri yang lebih tinggi dan mempunyai kadar prostaglandin dua kali lebih banyak dalam aliran darah (menstruasi) dibandingkan dengan wanita yang tidak mengalami nyeri haid. Uterus berkontraksi lebih sering sehingga menyebabkan peningkatan aktivitas uterus abnormal kemudian aliran darah menjadi berkurang sehingga terjadi iskemia yang menimbulkan nyeri. Proses terjadinya nyeri lainnya disebabkan oleh prostaglandin $\left(\mathrm{PGF}_{2)}\right.$ dan hormon lain yang menyebabkan saraf sensori nyeri di uterus menjadi hipersensitif (Chiu et al., 2017).

Kadar vasopressin meningkat saat menstruasi pada dismenore primer, apabila disertai peningkatan kadar oksitosin, kadar vasopressin yang lebih tinggi menyebabkan ketidakteraturan kontraksi uterus yang mengakibatkan adanya hipoksa dan iskemi uterus. Pada dismenore primer tanpa ada peningkatan prostaglandin maka akan terjadi peningkatan aktivitas alur 5-lipoksigenase dan meningkatkan sintesis leukotriene yang merupakan vasokonstritor sangat kuat yang menimbulkan kontraksi otot uterus (Chiu et al., 2017; Lowdermilk et al., 2015).

Penatalaksanaan dimenore yaitu hindari stress. Stress dapat menimbulkan dampak postif dan negative, dampak postifi seseorang menjadi termotivasi utnuk melakuakn sesuatu. Sedangkan dampak negative nya adalah membuat kesehatan terganggu sehingga berdampak secara psikologis yaitu cemas maupun depresi (Anurogo, D \& Wulandari, A, 2011). Pola makan yang teratur dengan gizi yang memadai. Mengkonsumsi makanan dengan gizi seimbang dapat meningkatkan kesehatan. Sayur dan buah-buahan guna meningkatkan kualitas hidup seseorang (Lowdermilk et al., 2015). Istirahat yang cukup, tidak kelelahan dan pembatasan penggunaan energi secara berlebihan dengan menerapkan pola tidur 6-8 jam sehari sesuai dengan kebiasaan (Anurogo, D \& Wulandari, A, 2011). Olahraga secara teratur, olahraga membantu mengurangi rasa tidak nyaman pada menstruasi melalui peningkatan vasodilatasi dan penurunan iskemia. Olahraga juga dapat melepaskan beta-endorfin, menekan prostaglandin dan mengalirkan darah dari organ dalam sehingga mengurangi kongesti panggul, salah satu olahraga yang disarankan oleh perawat adalah goyang pangggul (Lowdermilk et al., 2015).

Visualisasi diri dilakukan menjelang haid yaitu visualisasi bahwa dismenore tidak menimbulkan sakit dan tidak akan mengganggu aktivitas. Pemusatan pikiran (distraksi) bahwa haid tetap nyaman dan bisa beraktivitas seperti biasa dengan baik. Hal ini akan menyebabkan tubuh bereaksi membentengi diri sehingga dismenore dapat terjadi tanpa nyeri. Hal ini dapat dilakukan dengan mendengarkan musik, 
membaca buku atau menonton film juga dapat membantu mengurangi rasa sakit (Anurogo, D \& Wulandari, A, 2011). Pijatan dapat mengurangi nyeri melalui relaksasi otot paraverbra dan meningkatkan suplai darah panggul. Usapan lembut secara ritmik pada perut berguna untuk memberikan distraksi (Lowdermilk et al., 2015). Pil kontrasepsi oral mencegah ovulasi dan dapat mengurangi jumlah aliran menstruasi. Hal ini akan mengurangi jumlah prostaglandin, sehingga mengurangi dismenore. Pil kontrasepsi oral dapat digunakan sebagai pengganti Non Steroid Anti Inflamasi (NSAI) (Lowdermilk et al., 2015).

\subsection{Pengukuran Intensitas Nyeri}

Intensitas nyeri merupakan gambaran seberapa hebat nyeri dirasakan oleh individu, pengukuran intensitas nyeri sangat subjektif dan kemungkinan nyeri dalam intensitas yang sama dirasakan sangat berbeda oleh dua orang yang berbeda (eloise carr, mandy layzell, 2013). Beberapa skala yang dapat dipakai untuk mengukur skala nyeri diantaranya Verbal Descriptor Scale (VDS). VDS menggunakan kata-kata seperti "tidak nyeri, "nyeri sedang", atau "nyeri hebat" untuk membantu mendeskripsikan intensitas nyeri pasien. Penggunaan skala ini, pasien harus mengerti arti kata yang diucapkannya (Yvonne, 2007).

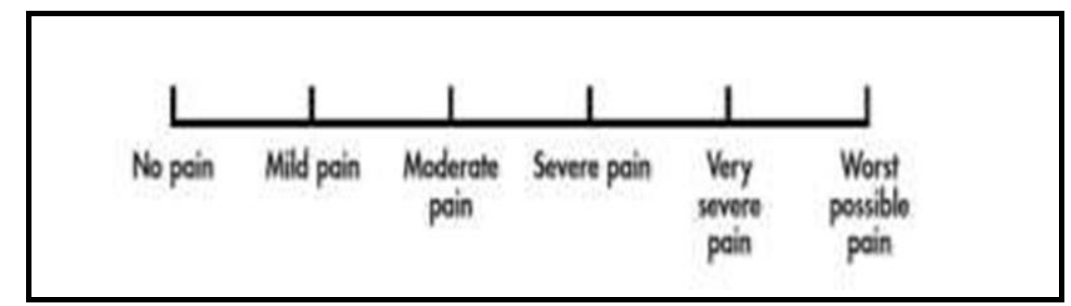

Gambar 1. Verbal Descriptor Scale.Sumber : Yvonne (2007)

Faces Pain Scale yaitu skala faces secara umum digunakan untuk pasien anak-anak yang tidak mengerti dalam menggunakan numeric pain scale. Pasien diminta untuk menunjuk pada gambar yang mendeskripsikan nyeri yang mereka ekspresikan (Yvonne,2007).

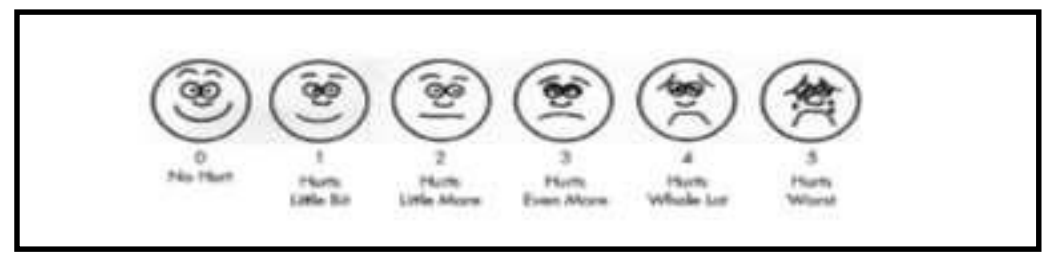

Gambar 2. Faces Pain Scale .Sumber : Yvonne (2007)

Visual Analog Scale (VAS) adalah sebagai garis sepanjang $10 \mathrm{~cm}$, dengan atau tanpa tanda pada tiap centimeter. Tanda pada kedua ujung garis ini dapat berupa angka atau pernyataan deskriptif. Ujung yang satu mewakili tidak ada nyeri, sedangkan ujung yang lain mewakili rasa nyeri terparah yang dialami (Potter \& Perry, 2006). 


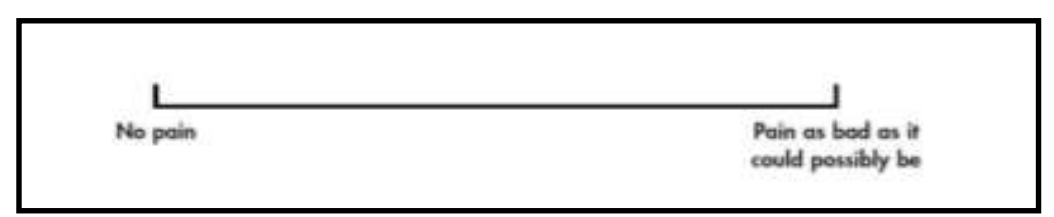

Gambar 3. Visual Analog Scale (VAS).Sumber : Yvonne (2007)

(a) Numerik Rating Scale (NRS)

Numerik rating scale menggunakan angka-angka nol sampai sepuluh untuk menggambarkan tingkat nyeri. Skala numerik verbal lebih bermanfaat pada periode pasca bedah, karena secara alami kata-kata tidak terlalu mengandalkan koordinasi visual dan motorik. Skala verbal dalam menggambarkan tingkat nyeri menggunakan kata-kata dan bukan garis atau angka.

Skala yang digunakan dapat berupa tidak ada nyeri, nyeri sedang, nyeri berat terkontrol, dan nyeri berat tidak terkontrol. Redanya nyeri dapat dinyatakan sebagai sama sekali tidak hilang, sedikit berkurang, cukup berkurang, baik atau nyeri hilang sama sekali. Skala ini membatasi pilihan kata pasien oleh karena itu skala ini tidak dapat membedakan berbagai tipe nyeri (Miller, 2009).

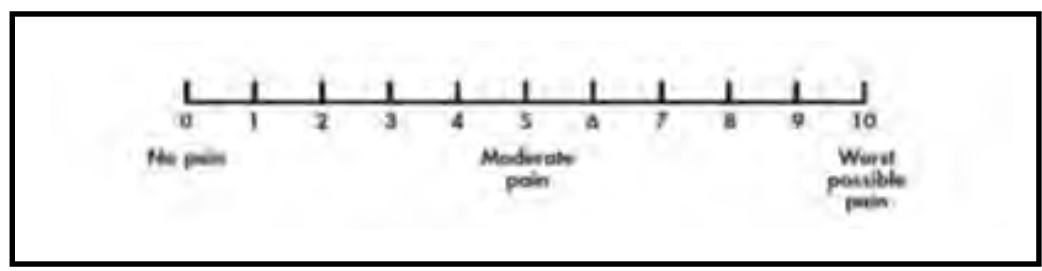

Gambar 4. Numerik Rating Scale. Sumber : Yvonne (2007)

\section{METODE}

Pendekatan yang digunakan adalah pengabdian kepada masyarakat dimana data diolah menggunakan pendekatan kuantittif yaitu metode Quasi Exsperimen dengan pendekatan prestet postest. Pada masyarakat diawali dengan pre-tes dan setelah pemberian perlakuan diadakan pengukuran kembali atau post test. Metode yang digunakan untuk mengukur keberhasilan intervensi adalah dengan membandingkan tingkat nyeri sebelum dan sesudah dilakukan latihan Cat Stretch Exercise. Pengambas ini dilakukan pada siswa di Pondok Imam Bukhori Selokaton Gondang Rejo pada bulan November 2018.

\section{HASIL}

Skala nyeri dismenore sebelum dan sesudah Cat Stretch Exercise (CSE) yaitu sebagai berikut: 
Tabel 1. Distribusi Frekuensi Skala Nyeri Sebelum dan Sesudah Cat Stretch Exercise (CSE) $(\mathrm{n}=31)$

\begin{tabular}{ccccc}
\hline \multirow{2}{*}{ Skala Nyeri } & \multicolumn{2}{c}{ Sebelum } & \multicolumn{2}{c}{ Sesudah } \\
\cline { 2 - 5 } & F & \% & F & \% \\
\hline Ringan & - & - & 28 & 90,3 \\
Sedang & 24 & 77,4 & 3 & 9,7 \\
Hebat & 7 & 22,6 & - & - \\
\hline Total & $\mathbf{3 1}$ & $\mathbf{1 0 0}$ & $\mathbf{3 1}$ & \\
\hline
\end{tabular}

Berdasarkan tabel diketahui bahwa mayoritas skala nyeri dismenore sebelum Cat Stretch Exercise (CSE) menunjukan skala nyeri sedang sebanyak 24 responden $(77,4 \%)$ dan mayoritas skala nyeri dismenore primer sesudah Cat Stretch Exercise (CSE) menunjukan skala nyeri ringan sebanyak 28 responden $(90,3 \%)$.

\section{PEMBAHASAN}

Exercise merupakan salahsatu intevensi terapeutik yang aman digunakan karena menggunakaan proses fisiologis, CSE berhasil dalam menurunkan nyeri haid (dismenore primer). Cat Stretch Exercise yang merupakan bagian dari Abdominal Strteching Exercise. Cat Stretch Exercise yang dilakukan pada saat dismenore mampu meningkatkan kekuatan otot rahim, daya tahan otot dan fleksibilitas otot (Fauziah, 2015; Studi et al., 2017; Utami, 2014) kemudian dapat meningkatkan kebugaran tubuh, optimalisasi daya tangkap, mengurangi ketegangan otot (kram), meringankan nyeri otot, dan serta mengurangi rasa sakit pada saat menstruasi (dismenore) (Vispute et al., 2011).

Cat Stretch Exercise merupakan salah satu gerakan exercise yang dipercaya dapat menurunkan dan menghilangkan nyeri menstruasi (dismenore). Cat stretch exercise yang dilakukan 5 kali berturut turut saat nyeri mulai dirasakan, dapat merelaksasikan otot uterus dan meningkatkan aliran darah ke Rahim, sehingga tidak terjadi metabolisme anaerob yang menghasilkan asam laktat. Hal ini menyebabkan impuls nyeri yang diterima serabut nyeri tipe $\mathrm{C}$ tidak adekuat. Akibatnya pengeluaran substansi P dihambat, sehingga pintu gerbang substansia gelatinosa ( $S G$ Gate) tertutup dan terjadi penurunan informasi intensitas nyeri yang dipersepsikan ke korteks cerebri sehingga nyeri akan berkurang (Chiu et al., 2017; Fauziah, 2015; Iacovides et al., 2015; Utami, 2014)

\section{KESIMPULAN DAN SARAN}

\subsection{Kesimpulan}

Cat Stretch Exercise (CSE) dapat menurunkan skala nyeri pada responden.

\subsection{Saran}

Hasil pengabdian masyarakat ini adalah implementasi dari sebuah penelitian, sehingga Cat Stretch Exercise (CSE) dapat dilanjutkan sebagai intervensi mandiri untuk mengurangi nyeri dismenore. 


\section{UCAPAN TERIMA KASIH}

Ucapan terimakasih disampaikan kepada Rektor Universitas Kusuma Husada Surakarta, Dekan Fakultas Ilmu Kesehatan, LPPM Universitas Kusuma Husada Surakarta, tempat penelitian Pondok Imam Bukhori, mahasiswa yang telah membantu dalam penagbdian masyarakat ini serta semua pihak yang tidak bisa disebutkan satu persatu.

\section{DAFTAR RUJUKAN}

Chiu, M. H., Hsieh, H. F., Yang, Y. H., Chen, H. M., Hsu, S. C., \& Wang, H. H. (2017). Influencing factors of dysmenorrhoea among hospital nurses: A questionnaire survey in Taiwan. BMJ Open, 7(12), 1-8. https://doi.org/10.1136/bmjopen-2017-017615

Davidson, M., London, M. L., \& Wieland, P. A. (2012). Maternal-Newborn Nursing \& Women's Health.

Eloise Carr, Mandy Layzell, Martin Christensen. (2013). Advancing nursing practice in paint management. In Blackwell publsihing Ltd: Vol.No.3.

Fauziah, M. N. (2015). Pengaruh Latihan Abdominal Stretching Terhadap Intensitas Nyeri Haid (Dismenore) pada Remaja Putri di SMK Al Furqon Bantarkawung Kabupaten Brebes. 1-108. http://repository.uinjkt.ac.id/dspace/handle/123456789/28982

Iacovides, S., Avidon, I., \& Baker, F. C. (2015). What we know about primary dismenore today: A critical review. Human Reproduction Update, 21(6), 762778. https://doi.org/10.1093/humupd/dmv039

Lowdermilk, D. leonard, shannon E. perry, \& Cashion, K. (2015). Introduction to Maternity \& Women's Health Care UNIT TWO Women's Health Complications of Pregnancy.

Puspita, L., \& Anjarwati, T. (2019). Pengaruh Latihan Abdominal Stretching Terhadap Intensitas Nyeri ntensitas Nyeri Haid pada Siswi SMK Pelita Gedongtataan Kabupaten Pesawaran. Wellness and Healthy Magazine, 1(February), $41-47$. https://wellness.journalpress.id/wellness/article/view/v1i218wh

Studi, P., Diploma, K., \& Kesehatan, F. I. (2017). Penanganan Dysmenorhea Di Pesantren As-Syalafiah.

Utami, E. E. (2014). Pengaruh Tehnik Cat Stretch Exercise Terhadap Intensitas Nyeri Dismenore Pada Remaja di SMA Muhammadiyah 2 Yogyakarta. Sekolah Tinggi Ilmu Kesehatan 'Aisyiyah Yogyakarta. 
Vispute, S. S., Smith, J. D., Lecheminant, J. D., \& Hurley, K. S. (2011). The effect of abdominal exercise on abdominal fat. Journal of Strength and Conditioning Research, 25(9), 2559-2564. https://doi.org/10.1519/JSC.0b013e3181fb4a46

Wong, C. L. (2018). Health-related quality of life among Chinese adolescent girls with Dysmenorrhoea. Reproductive Health, 15(1), 1-10. https://doi.org/10.1186/s12978-018-0540-5

Yvonne. 2007. Pain Management Evidence-Based Tools and Techniques for Nursing Professionals 